\title{
EL PAISAJE EN LA ERA DEL ANTROPOCENO: EL VIDEOPAISAJE TECNORROMÁNTICO
}

Cristina Sanz Martín

Universidad de Málaga

Data recepción: 2019/01/29

Data aceptación: 2019/08/07

Contacto autora: cristinasanz@usal.es

ORCID: https://orcid.org/0000-0002-5225-6847

\section{RESUMEN}

Vivimos en una nueva era geológica -el Antropoceno- y una nueva sociedad con su correspondiente mentalidad, consciencia y forma de ver el mundo. En cambio, se sigue representando e interpretando el paisaje a través de los códigos heredados de la historia del arte, primordialmente, aquellos del siglo XIX tomados del Romanticismo, ignorando, de este modo, la realidad actual. Se ha identificado un nuevo tipo paisaje que hasta ahora no ha sido estudiado. Este artículo trata sobre las propuestas artísticas que aúnan videoarte y paisaje en la tradición occidental, particularizando en aquellas que reinterpretan el imaginario romántico en el contexto de la era tecnológica. Se pretende estudiar y contextualizar el paisaje contemporáneo, el cual ha sido víctima de un uso muy heterogéneo y confuso desde la Posmodernidad. Habiéndose apropiado de él en los últimos años muy diversas ciencias, desde la geografía hasta el urbanismo, proponemos una revisión del mismo desde la teoría del arte.

Palabras clave: paisaje, vídeo, tecnorromanticismo, antropoceno, arte

\section{ABSTRACT}

We live in a new geological era, the Anthropocene, and in a new society with its corresponding attitudes, consciousness and way of seeing the world. Nevertheless, we continue to represent and interpret the landscape through codes inherited from the history of art, mainly those that the 19th century took from Romanticism. In doing so, we ignore the reality of today. We have identified a new kind of landscape that has yet to be studied. This paper addresses artistic proposals that bring together video art and landscape in the Western tradition, focusing on practices that reinterpret the romantic imaginary within the context of the technological era. The aim is to study and contextualize the contemporary landscape, which has been used in a very confusing and diverse way since the advent of Postmodernism. Having been appropriated by many different sciences in the last few years, from geography to urbanism, we propose a review of the landscape based on the theory of art.

Keywords: landscape, video, Technoromanticism, Anthropocene, art 
El órgano con el que he comprendido el mundo es el ojo'. Goethe

Parece que hemos olvidado que el paisaje surgió como un género pictórico, con su correspondiente definición y con sus características propias como corresponde a todo género, pero ha ido sufriendo un cierto desentendimiento por parte del arte contemporáneo en cuanto a su identidad y autonomía y una apropiación errada por parte de todos los demás campos, desarraigándolo de su verdadero sentido y otorgándole nuevos y dispares significados. Además, no podemos pretender que el modo en el que miramos hoy al paisaje y a la naturaleza sea el mismo en el que nuestros antepasados miraron al paisaje pictórico y a la naturaleza. ¿Cuál es el paisaje que representa a la era contemporánea? ¿Cómo son los códigos, la narrativa, el lenguaje y la estética de aquellos que están creando una nueva tradición paisajista que sí representa al hombre del Antropoceno? La hipótesis que plantea este trabajo es que ha surgido un nuevo tipo de paisaje y que hasta ahora no ha sido estudiado por los teóricos del arte.

La principal problemática que se plantea hoy día es la de reducir el paisaje a un sinónimo de naturaleza. Es alarmante ver cómo en las últimas décadas se ha asumido de forma colectiva una idea errada del concepto. Con frecuencia, en muy diversas esferas de la sociedad encontramos cómo se asume la existencia del mismo como una realidad geográfica, mediante el empleo de términos como, por ejemplo, «paisaje natural» o «paisaje físico», entre otros. Existe una creencia común en una «naturalidad» del paisaje, creencia bien anclada y difícil de erradicar, a pesar de que sea continuamente desmentida por numerosas prácticas (Cauquelin 2013, VI). Y, aún más preocupante, resulta la frecuencia con la que encontramos estas premisas dentro de la especialización de Arte. A diferencia de lo frecuentemente asumido, el paisaje no puede ser natural porque no existe de forma natural. Urge aclarar que el paisaje no existe per se, sino es un constructo creado a través de la tradición cultural y que se fue desarrollando con el paso de muchos siglos, gracias, también, al desarrollo tecnocientífico. El paisaje, para constituirse como ente, precisa de un sujeto que lo interprete. Hoy en día el término se ha diluido hasta abarcar cosas tan dispares como turismo, ecología, urbanismo, sostenibilidad o sociología (Maderuelo 2005, 38), como si hubiésemos olvidado que el paisaje fue un género que nació con las bellas artes. Otra de las problemáticas que motivaron este trabajo es que gran parte de las prácticas que hemos analizado a lo largo de esta investigación son, relativamente, muy recientes. La gran mayoría fueron creadas en la última década. Paradójicamente, estos nuevos paisajes sí han entrado dentro del circuito del arte: se escribe sobre ellos en magazines digitales -que se acercan más al periodismo que a la ciencia-, los artistas han llegado a las galerías, participan en las ferias de arte y comienzan a formar parte de los fondos de los mejores museos de arte contemporáneo como el MoMA. Pero se ha detectado un gran vacío en cuanto a un estudio riguroso de las mismas desde la teoría del arte. Existe una necesidad urgente de que estos nuevos paisajes sean estudiados desde el ámbito académico.

Aunque a lo largo del curso de esta investigación se han identificado diferentes tipos de paisaje en el panorama del arte contemporáneo, en este artículo nos centraremos en tratar el que hemos denominado "paisaje tecnorromántico". Sintetizaremos este amplio campo a través de la obra de cuatro videoartistas.

Hablar de paisaje implica hablar de cultura, de historia, de tradición, de literatura, de creencias religiosas, de filología, de percepción, de ciencia, de filosofía, de poesía, de bellas artes, especialmente de historia de la pintura, pero también de fotografía, y no solo. El paisaje es una encrucijada donde convergen un sinfín de disciplinas. Surge a partir de un esfuerzo perceptivo, que está determinado, además, por la condición socioeconómica del individuo y su bagaje cultural. Solo al realizar un ejercicio subjetivo, al proyectar el ser humano toda su tradición cultural y sus sentimientos en el entorno, este se convierte en "paisaje". El paisaje tiene dos dimensiones: lo físico, lo que nos rodea, y lo cultural, algo que concierne directamente a la interpretación del individuo (Maderuelo 2003, 23 y 25). El paisaje no es la naturaleza: la naturaleza es el conjunto de elementos naturales que encontramos en el territorio y paisaje el resultado de la subjetivización de un territorio. Para llegar a esta subjetivización 
se necesitan herramientas constructoras de pensamiento, como la filosofía, la literatura, la religión o el arte. Como recuerda A. Roger citando a René-Louis de Girardin: "hay país y paisaje, como hay desnudez y desnudo" (Roger 2007, 22).

El reconocido paisajista Javier Maderuelo explica que el paisaje es un concepto inventado o, mejor dicho, una construcción cultural. No es un mero lugar físico, sino el conjunto de una serie de ideas, sensaciones y sentimientos que elaboramos a partir del lugar. El paisaje reclama una interpretación, un juicio estético desinteresado y la presencia de una emotividad, que es el resultado de la proyección emocional del artista y del espectador sobre el medio. De este modo, en la tradición occidental, el paisaje se va desarrollando paralelamente a los avances pictóricos hasta originar un género que cobrará particular fortuna a partir del siglo XVII, alcanzando su máxima expresión en el XIX con el Romanticismo, el Impresionismo (Maderuelo 2005, 38) y la irrupción de la fotografía, que participa profusamente en la configuración del paisaje contemporáneo (fig. 1).

No podemos olvidar la hibridación que experimentan las artes en la era contemporánea. La mezcla de territorios, la ausencia de fronteras entre los campos son una característica de nuestra era. Y el paisaje no se escapa de esta regla. Su esfera se ha ampliado y ofrece un panorama mucho más amplio, como es el caso de la incursión de las nuevas tecnologías audiovisuales que ofrecen versiones diferentes del paisaje. Lejos de que esta expansión relegue el paisaje a un segundo plano, estas incorporaciones evidencian muy bien cómo el paisaje es fruto de un largo, complejo y paciente aprendizaje y cómo depende de múltiples campos (Cauquelin 2013, VI). Este giro tecnológico que el arte experimenta, de acuerdo con la sociedad de su tiempo, ayuda a contradecir y desmontar sus mitos: la tecnología pone en evidencia la artificialidad de la construcción del paisaje. El hecho de que las obras precisen de una notoria cantidad de trabajo (imágenes captadas por la cámara, trabajadas en un ordenador mediante algoritmos matemáticos, inclusión de escenas y cortes o mezcla de diferentes técnicas de producción y reproducción) para alcanzar a reproducir un paisaje que, digamos, podríamos ver de manera natural sin todo este trabajo, es una

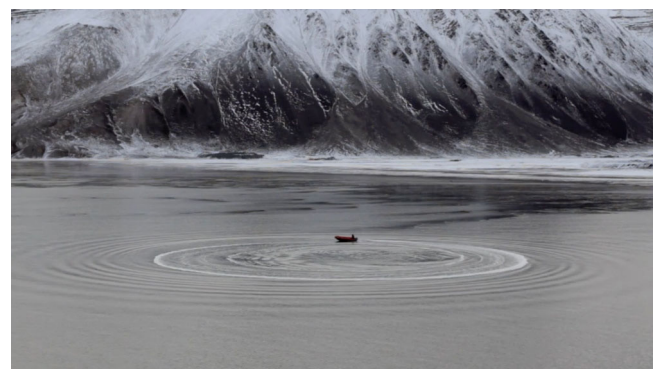

Fig. 1. Lukas Marxt, Reign of Silence, 2013. Vídeo, color (7'), sonido, triología (https://vimeo.com/82123342)

evidencia de todo el trabajo que hay detrás sin que nos percatemos. Y, sin duda, convendría seguir la pista de lo que la tecnología esconde tras nuestras creencias de "natural", para entender mejor este entramado que se oculta (Cauquelin 2013, XII-XIII).

Somos conscientes de que podría parecer desacreditador empezar hablando de "género" dentro del seno del arte contemporáneo, pero al rescatar el paisaje en el contexto del género videográfico, no se pretende reconstruir un discurso sectario en la línea del academicismo del XIX que reconstruya fronteras entre las artes, sino, revisar los géneros desde del pensamiento abierto e híbrido del siglo XXI. A partir de la aceptación de la consanguinidad de las artes que caracteriza a la época transmedia, se propone estudiar los trabajos desde su propia identidad y sus características individuales. Mediante esta revisión se pretende identificar las problemáticas existentes en el panorama actual y, así, garantizar una correcta preservación de las obras.

Todos los nuevos medios -fotografía, videoarte, arte digital o cine- han heredado esas características que cada género pictórico defendía y que, aún hoy, a pesar de la eliminación de las barreras de las artes y la hibridación de los temas y los formatos, permiten separar las obras en líneas temáticas. Y, precisamente, lo más interesante es que no solo han heredado los géneros, sino que en muchas ocasiones los artistas contemporáneos también los han cuestionado, problematizado y transformado. Pero incluso esas obras más reivindicativas son reconocibles aún dentro de estas "líneas temáticas». Así pues, es de este modo como debemos tomar el concepto de "género" 
hoy día, simplemente como una manera de diseccionar y catalogar las obras artísticas que presenten características y propósitos comunes. Esta no será una clasificación hermética y sectaria, pero es necesario establecer algún tipo de catalogación para abarcar de alguna forma el estudio de un tema tan amplio como puede ser el videoarte.

Por otro lado, este trabajo de investigación surgió también motivado por un interés antropológico. Si el paisaje desborda los límites de ser un mero género pictórico, si es un constructo y un constructor cultural, a su vez, creador de identidad cultural, tiene que ser, por ende, también estudiado desde la antropología. Esto es algo que los historiadores del arte han pasado por alto hasta ahora. Este trabajo defiende que existe un lazo que desborda los límites del arte y hunde sus raíces en la pura antropología, vinculando al hombre y a la naturaleza de la forma más primigenia posible. No podemos obviar que el paisaje no es nuevo, así como no podemos negar que es novedad. Debemos identificarlo correctamente y analizarlo a partir de una interpretación adecuada. Como defiende el historiador del arte Simon Schama: "[el paisaje] es un texto donde las generaciones escriben sus repetitivas obsesiones" (Balsom 2018).

Este trabajo de investigación surgió a partir de una serie de interrogantes como: ¿tenía que ver el resurgimiento que está viviendo el paisaje con que a lo largo de la historia los periodos de mayor auge para el género han acaecido tras épocas de grandes desarrollos tecnocientíficos? ¿Es este resurgimiento una "copia" del paisaje heredado del romanticismo, o si, por lo contrario, estamos viviendo -debido al contexto histórico- un "resurgimiento" de esas necesidades intrínsecas al ser humano que le llevan a acudir a la naturaleza? En lo que respecta, en específico, al paisaje de corte tecnorromántico, la respuesta, probablemente, es: ambas. Es incuestionable que la herencia romántica está en nuestra cultura. Pero, tras haber analizado detenidamente el Antropoceno en contraposición a épocas pasadas, no hay duda de que hay "algo" que solo se puede explicar desde la antropología. "Algo" que vincula al ser humano con la naturaleza desde el principio de los tiempos. De hecho, esta simple observación, esta visión de ver una "vinculación" entre hom- bre y naturaleza ya parte de un punto de vista culturamente construido y que es representativo de nuestra tradición cultural, puesto que hoy día aún hay sociedades -e incluso en Europa también las hubo un día- que todavía poseen una idea de la naturaleza y del hombre como uno solo. En cambio, nosotros hace mucho tiempo que las separamos, véase, por ejemplo, como Platón ya distinguía entre "el mundo de las ideas" y "el mundo de las cosas", como si fueran dos ámbitos completamente separados ${ }^{2}$. De este modo, nos atrevemos a decir que es cíclico que siempre tras épocas de grandes avances el ser humano acude a la naturaleza a buscar su propia identidad y reconectar consigo mismo, véase, por ejemplo, cómo el Romanticismo surge tras el desarrollo de la Revolución Industrial. Igualmente, por ejemplo, muchos investigadores entre los que destaca indudablemente Omar Calabrese y su tesis de "Neobarroco", defienden que vivimos un contexto sociocultural similar al de la crisis del siglo XVII, momento en el que, por cierto, tiene lugar el primer gran reconocimiento de la pintura de paisaje de la mano de artistas como Jacob van Ruisdael (1628-82) o Claudio de Lorena (1600-82).

Tras analizar la praxis contemporánea, hemos detectado que, de los diferentes tipos de videopaisaje, el paisaje tecnorromántico es el que más pone la mirada en el pasado. Pero, a pesar de inspirarse en los códigos estéticos y narrativos propios del Romanticismo, no ha permanecido estático y ha reinventado su discurso. Los artistas no solo se han servido del avance tecnocientífico, sino también han transformado los códigos de antaño utilizándolos como una plataforma para proyectar las inquietudes que preocupan a la sociedad contemporánea como, por ejemplo, el tema de la percepción ${ }^{3}$. Las preocupaciones en torno a las teorías de la percepción son uno de los rasgos más característicos del videopaisaje del Antropoceno, que, además, le desmarca de toda la herencia paisajista que le precede: la preocupación de los artistas por entender cómo el individuo percibe el mundo, el esfuerzo por comprender cómo funciona la mente y cómo el individuo gestiona la información que recibe. Además, aquí la importancia de este proceso mental se enfatiza debido a que, en el caso del paisaje, ese "entorno" que percibe constituye el elemento esencial de identidad del género. 


\section{Primera etapa del videoarte: "Paisajes como instrumento de estudio"}

Tras el análisis de la praxis hemos detectado una diferencia entre los paisajes de la primera época del videoarte y los de la segunda4. En la primera época hemos clasificado paisajes que hemos denominado: "paisajes como instrumento de estudio". Este tipo de paisajes son más comunes en los inicios del vídeo debido a dos razones: por un lado, durante los primeros años del vídeo, lo importante no era el contenido de las obras sino todo el engranaje técnico y formal. Y, por otro lado, el cambio de conciencia que ha experimentado la sociedad en los últimos años. La sociedad empezaría, paulatinamente, a entender la crisis medioambiental y esto se evidenciará en la praxis, enfatizándose en la segunda etapa. Algo que, además, está relacionado con la tesis antropológica que brevemente introducíamos. Pero hemos de recordar que los videoartistas no fueron los primeros en «objetivizar» la naturaleza y utilizar el paisaje como medio para investigar otras cuestiones. Ya los impresionistas, por ejemplo, utilizaron la naturaleza como un medio para llevar a cabo otras investigaciones como el estudio de la luz o la tematización de la mirada5.

Mary Lucier (Ohio, 1944) es considerada como una de la primeras videopaisajistas. Pero tras haber estudiado su obra, nos atrevemos a decir que la naturaleza no era el fin de su trabajo, sino un medio para llevar a cabo otras investigaciones. Teniendo la ocasión de conocer a la artista ${ }^{6}$, le preguntamos qué le llevaba a trabajar el paisaje y por qué a través del vídeo. Sorprendentemente, su respuesta cambió el curso de la investigación y, entonces, establecimos una nueva rama de interpretación para el paisaje del Antropoceno, la de "paisajes como instrumento de estudio", pues no era la única artista:

En los primeros días, solo teníamos una bailarina, nosotros mismos, y el paisaje. (Ríe). Trabajé mucho con bailarines [...] Pero el paisaje es interesante. Mi último marido era un pintor de paisajes [...] Así que pensé mucho sobre paisaje, me pregunté por qué seguía trabajando con él. En primer lugar, porque estaba ahi, y en segundo, porque es algo que está en peligro. [...] Los elementos del paisaje me permiten proyectar mis propios sentimientos?.
Como podemos comprobar a través de las palabras de la propia artista, es evidente que sí le preocupa la naturaleza y siente una sensibilidad por ella. Pero que no acude a ella por un deseo expreso. Lo que más ha preocupado a Mary Lucier a lo largo de su carrera es la luz. La luz como un agente de la percepción visual y de la memoria. También reexaminar la cultura a través del paisaje y la lente de su videocámarå. A través de sus palabras, se siente que la naturaleza es como si fuese un recurso al que llegó casi por inercia, "porque estaba ahí". De hecho, la magnífica obra paisajística de Mary Lucier, puesto que aquí no se pretende poner en cuestión y se reconoce la calidad de su larga trayectoria, es también un continuo homenaje a la historia del arte. Tiene obras homenajeando a los pintores románticos -por ejemplo, Wilderness (1986), que aquí analizaremos-, a los pintores impresionistas, como Ohio at Giverny (1983), una de sus obras más conocidas, y que recrea un jardín de Monet. O al paisajismo americano del XIX y del XX, como, por ejemplo, The plains of Sweet Regret (20042007), donde se sirve de la herencia de la historia del arte y del imaginario colectivo americano con esos paisajes que tanto nos recuerdan a Hopper con esas infinitas llanuras y esas casas tan características en medio de los campos. Ella, puede ser que debido a su carácter pionero, no estaba centrada en crear una nueva tradición paisajística, sino estaba más preocupada por descubrir las posibilidades que le brindaban la cámara de vídeo y la imagen en movimiento e investigar otros campos como, por ejemplo, el interés que ha tenido a lo largo de toda su carrera por la luz -véase, Dawn Burn, 1975-. Para ello se sirve de herramientas "que estaban ahí" como la herencia de la historia del arte, homenajeando a sus predecesores, o la naturaleza: "[Esto] me llevó a un interés por las videoinstalaciones, ya que engloban todo en lo que yo estaba interesada: tiempo, espacio, sonido y luz. Hice mi primera videoinstalación en 1973" (Barlow 2000, 233).

Wilderness $\left(1986,20^{\prime}\right)$ es una de sus mejores representaciones de videopaisaje y uno de los primeros videopaisajes de la historia. Es un homenaje a la tradición americana de paisaje. Una revisión del mito pastoral americano a través de la lente de una tecnología contemporánea. Forma parte de una serie de trabajos que exploran 


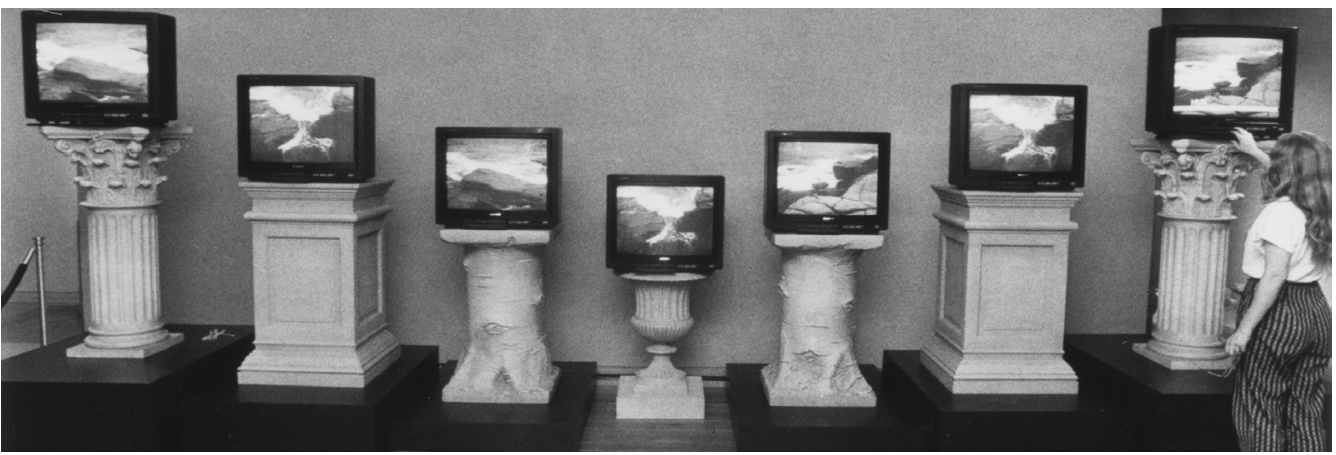

Fig. 2. Mary Lucier instalando Wilderness, 1986. Videoinstalación 7 canales, color (20'), sonido

la percepción visual y la memoria a través de la luz y el paisaje. Esta instalación se centra en un conjunto de motivos paradigmáticos derivados de las pinturas de la Escuela del Río Hudson -máxima representante del paisaje pictórico romántico americano- y las escuelas luministas de mitad del XIX (fig. 2) (Barlow 2000, 147).

Wilderness es una videoinstalación que consiste de tres series de vídeos sincronizados y reproducidos en siete monitores. Estos monitores están montados sobre pedestales, y los pedestales sobre plataformas que alzan su altura a diferentes niveles. En el centro de la instalación hay una urna de jardín acanalada, flanqueada por dos columnas en hilera que alzan la altura. Estas plataformas tienen forma de pedestales clásicos, troncos de árboles en yeso y, en el centro, una urna de jardín (Barlow 2000, 148). Los tres canales de vídeo están distribuidos a lo largo de esta formación de monitores. Las series de vídeos se organizan en el orden de $\mathrm{A} / \mathrm{B} / \mathrm{A} / \mathrm{B} / \mathrm{C} / \mathrm{B} / \mathrm{C}$, haciendo así posible el complejo intercambio entre la narrativa temporal y la vista de paisaje. Las cintas están estructuradas como un viaje de la cámara a lo largo de las geografías interiores y costeras del noreste, llegando hasta las bahías del norte de la isla de Terranova. En cada lugar la cámara examina imágenes de naturaleza, industrias y hogar a través del amplio contexto de la relación del hombre con su medio. $\mathrm{Ha}$ intentado reconstruir en vídeo las condiciones exactas de ambiente, luz, y tiempo retratadas por los artistas a los que rinde homenaje y, al mismo tiempo, establecer un diálogo entre el pasado y el presente, lo mundano y lo poético, lo real y lo ideal (Barlow 2000, 147).
La naturaleza predomina las imágenes. Las cintas son en color, pero Lucier utiliza un brillo azul plateado para bañar las imágenes en una luz deslumbrante. El resplandor cristalino ligeramente agitado en un mar frígido con el que la cinta concluye con un final impotente. Las imágenes de icebergs, de la costa de Maine, de la orilla de Connecticut, del atardecer y de las colinas verdosas son de Lucier. Mientras que las demás derivan de paisajistas americanos del XIX como Frederic Chruch, Fitz Hugh Lane, Winslow Homer, Sanford Gifford o John Kensett. Periódicamente, las imágenes retroceden poco a poco en la pantalla, para ser capturadas en un marco dorado que simula un halo de beatificación. Hay también intrusiones derivadas de pinturas inglesas, como las naturalezas muertas de John Peto y William Harnett, y algunas referencias a pintores del XX de la América industrial, como Thomas Anschütz y Charles Sheeler (Barlow 2000, 149).

\section{Segunda etapa del videoarte: paisajes metafísicos}

La contemplación del mundo exterior siempre será clave para la supervivencia de cualquier especie $y$, por lo tanto, es un acto instintivo 9 . Gianfranco Foschino

En la segunda etapa, encontramos paisajes que, en general, muestran otro tipo de tratamiento de la naturaleza. Son obras que se centran más en el contenido que en los aspectos formales. Parten de una preconcepción de la naturaleza como un sujeto. Como un ente que necesita expresarse, al cual quieren darle voz. Pero también un medio para proyectar las cuestiones 
que a ellos les afligen metafísicamente como individuos. Los artistas visibilizan mediante el arte diferentes preocupaciones de nuestra sociedad. Además, reflejan también la toma de consciencia que surge en el Antropoceno de la naturaleza como algo que está en peligro y que debemos proteger.

Charly Nijensohn (Argentina, 1966) es un auténtico hombre del Romanticismo en el siglo XXI. Humanista, viajero de los de antaño, multidisciplinario e investigador. Se integra en la vida de las comunidades de los lugares a los que viaja como un auténtico antropólogo. Su trabajo es pura lírica audiovisual. Es existencialista, dramático y un tanto tétrico. Horizonte, vacío, soledad, el individuo frente a la inmensidad de la naturaleza. Sentimental, crítico, poético, real e irreal. Sensorial y analítico. Sus trabajos son poemas audiovisuales muy críticos. De hecho, su obra nos recuerda mucho a la de otro gran hombre tecnorromántico: Bill Viola, artista que hemos estudiado en esta investigación pero que no alcanzamos a incluir aquí. El trabajo de Charly Nijensohn es una búsqueda de respuestas a su propia existencia y a las respuestas cosmo-existenciales que le turban. Le preocupan las «llamadas preguntas de la condición humana» ${ }^{10}$.

A nivel formal, en su obra solemos encontrar una imagen partida en dos por la línea del horizonte. En Nijensohn el horizonte es el eje composicional de la imagen, organizando el espacio en una bidimensionalidad de cielo y tierra. En cuanto a la edición, el artista no manipula digitalmente sus imágenes. Su estilo de trabajo es plantear siempre una escena, donde no se presenta una narratividad evidente ${ }^{11} \mathrm{y}$, mediante la estimulación sensorial y emocional, remover la consciencia del espectador. Además, Nijensohn provoca siempre una situación donde hay un desafío entre el hombre y la naturaleza. A él le interesa retratar la insignificancia del ser humano ante la inmensidad de la naturaleza. Siempre elige lugares remotos, perdidos incluso en los mapas, para recrear estampas poéticas donde explorar temas muy críticos. Su estética puede ser romántica, pero, tras ese Romanticismo, se encuentra un artista contemporáneo donde lo conceptual es el germen de su trabajo. Sus obras son muy reivindicativas. Puede que no encontremos una gran narrativa,

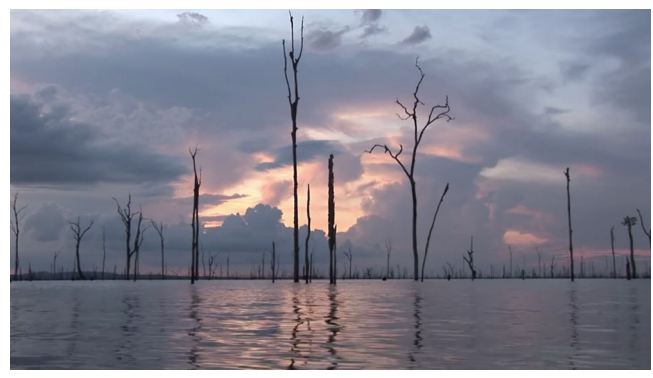

Fig. 3. Charly Nijensohn, Dead Forest, 2009. Vídeo, color (7' 07"), sonido (https://www.youtube.com/ watch?v=94fvxlHmpRc)

pero siempre hay un fortísimo mensaje. Por otro lado, el tiempo en Charly Nijensohn es un recurso fundamental. Sus obras son auténticos tableaux vivants. El tiempo es empleado como herramienta para que el mensaje cale profundamente en el espectador. Tiempo para que no se apresure y se relacione con la obra.

Las similitudes de su obra con los paisajes del siglo XIX son palpables a simple vista. Esto se evidencia muy bien en Dead Forest (2009, 7' $\left.07^{\prime \prime}\right)^{12}$, donde presenta unas reminiscencias románticas muy cercanas a la estética de Friedrich. A nivel formal, vemos esa imagen dividida en dos por la línea del horizonte. Agua, cielo, y árboles muertos que nos dan la sensación de estar en un cementerio, en un lugar en ruinas, muy de la estética romántica. Realza el mensaje que quiere transmitir enfatizando la imagen en la destrucción $\left(0^{\prime} 34^{\prime \prime}\right)$. En seguida presenta brevemente a dos siluetas negras flotando en el horizonte. A nivel general, observamos cómo comienza con una escena un tanto tétrica, para, de repente, incluir un plano de gran belleza que rompe la tónica de grises con colores rosados para contemplar la Aurora al despuntar con sus rosados dedos (fig. 3).

Estas características que hallamos en Nijensohn, pero que extendemos también a los demás artistas estudiados, nos remiten a la tesis de $\mathrm{R}$. Argullol. Ese desafío entre el hombre y la naturaleza, esa escisión, ese binomio de destrucción y belleza que encontramos en estas obras nos devuelven a "La atracción del abismo". En esta obra, Argullol defiende que el paisajismo romántico no es simplemente una genérica "pintura de paisaje", es, primordialmente, la representación 


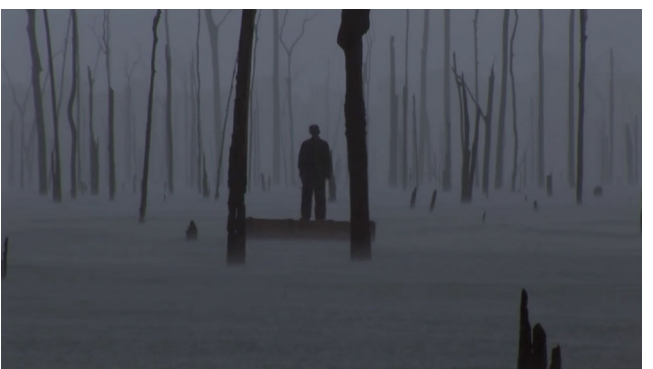

Fig. 4. Charly Nijensohn, Dead Forest, 2009. Vídeo, color (7' 07"), sonido (https://www.youtube.com/ watch?v=94fvxlHmpRc)

artística de una determinada comprensión de la naturaleza por parte de una sociedad. Por ello, el paisaje romántico deviene un escenario en el que se confrontan naturaleza y hombre y en el que este advierte la dramática nostalgia que le invade al constatar su ostracismo con respecto a ella. El hombre romántico ansía reconciliarse con la naturaleza, reencontrar su identidad en una infinitud que se muestra ante él como un abismo (Argullol $1983,14)$. Por tanto, nos encontramos en el siglo XVIII, más que con un simple cambio de estética, con un cambio de mentalidad, como el cambio de consciencia de la sociedad del Antropoceno al percatarse de la crisis medioambiental. Uno de los rasgos que más diferencia al paisaje romántico de toda la tradición precedente es, como explica Argullol, el concepto de «desantropomorfización»: el hombre ha perdido definitivamente su centralidad. Tras el Renacimiento y el siglo de las Luces, la naturaleza se torna trágica y despiadada. Frente al ambiente bucólico y sosegado que le precede, en el Romanticismo se produce una «escisión» entre el hombre y la naturaleza. En contraposición al escenario limitado y controlado, los horizontes se abren hacia el infinito y la inmensidad. El paisaje romántico es trágico. El hombre queda desposeído de la naturaleza, reconoce su insignificancia y se autominimiza ante el universo (Argullol 1983, 16-24). Pero, no obstante, aún anhela y busca la reconciliación entre ambos. La fascinación del romántico por la naturaleza está relacionada con la "doble alma" de esta: se siente atraído por la promesa de totalidad que ve en su seno, y, a la misma vez, por la violencia que la naturaleza lleva consigo (Argullol
1983, 112). El paisaje romántico es un canto a la belleza y la destrucción de la naturaleza.

Volviendo al análisis de la obra, en el minuto 1'05", vuelven a aparecer estos dos individuos sobre una plataforma, de negro, y dejándose llevar a la deriva. Los dos hombres se dan la espal$\mathrm{da}$, a pesar de estar juntos, simbolizan la soledad característica en Nijensohn. A este plano le vuelve a seguir otra escena desoladora y muy emocional: hay tristeza, se apela a las emociones del espectador una vez más. También hay tensión, creada por la contraposición de la belleza de la vista y una escena tan triste, desconcertante y melancólica. Después, vuelve a contraponer una secuencia placentera, pero la calma se interrumpe por una tormenta, en un plano donde la línea del horizonte vuelve a ser la única protagonista. Aparece un hombre flotando a la deriva en una imagen que guarda un fortísimo mensaje existencialista. Esto puede albergar multitud pensamientos y nos hace sentir muy insignificantes, desprotegidos y débiles ante la naturaleza. Si hasta ahora el autor había utilizado el recurso sonoro para potenciar la soledad mediante sonidos que recrearan "silencio" -pájaros piando, calma o agua- o para tensar la situación mediante los truenos amenazantes, ahora silencia y solo hay vacío, en consonancia con el vacío metafísico que intenta transmitir. Entonces, la tormenta vuelve y encontramos una vista del horizonte: un cementerio de árboles, la silueta negra del individuo a la deriva y la tormenta que parece la destrucción total. La angustia por la muerte amenazando a la vida que no se inmuta y por la fragilidad crean, junto a los recursos formales del audiovisual, un estado de tensión extraordinario. La obra acaba dejándonos a la deriva a nosotros e invitándonos a la reflexión.

Es imposible no remitirse a Friedrich en estas imágenes. Obras como Monasterio de cementerio en la nieve (1818) o Caminante ante un mar de niebla (1818) presentan una estética que guarda grandes paralelismos con la estética de Nijensohn (fig. 4). Pero las obras de Nijensohn van mucho más allá de la mera estética. Esconden un duro mensaje, una crítica metafísica y social. Nos habíamos referido al lugar como "un cementerio de árboles", y es que este lugar fue "asesinado" por el gobierno brasileño. Un lugar que no 
aparece ni en los mapas. Se encuentra en mitad del Amazonas, se trata del lago Umatuma. En la década de los setenta, el gobierno brasileño necesitaba abastecer de electricidad a Manaos. Para ello inundaron grandes territorios generando el que hoy es el lago artificial más grande de Latinoamérica. Estas tierras también eran el hogar ancestral de la tribu Waimiri- Atroari (Nijensohn 2015) -quienes, por cierto, se denominan "Kinja" -. Esta obra es una crítica social a la usurpación de territorios por parte del gobierno brasileño, pero también una crítica a la humanidad por la violación a la tierra en nombre del "progreso". Una crítica que representa la preocupación del Antropoceno por la inconsciencia de la sociedad post industrial, que sacrifica su propia supervivencia en pro del desarrollo.

Por su parte, su obra El naufragio de los hombres $^{13}\left(2008,7^{\prime} 28^{\prime \prime}\right)$ es pura lírica audiovisual. Una videoinstalación de tres proyecciones registrada en el altiplano boliviano, en el Salar de Uyuni, inundado durante el mes de lluvia (julio). Un espacio en el que los valores de la luz y el reflejo alteran la percepción. Un desierto blanco que parece un paisaje polar. Es un hecho que Bolivia prácticamente ya no cuenta con espacios de nieve, ni glaciares debido al calentamiento global (AA.VV. 2014, 45) (fig. 5).

Este auténtico tableau vivant tiene tres dimensiones: el espacio, el tiempo y lo metafísico. En esta obra la narratividad está más ausente que en ninguno de sus otros trabajos. De hecho, podríamos hablar de una obra meramente sensorial. Pero donde, por difícil que parezca, el mensaje sociocrítico es aún más fuerte que las cualidades formales que conforman su estética sublime. Nijensohn nos inmerge en un lugar tan peculiar que ni siquiera alcanzamos a esclarecer si estamos en el cielo caminando entre las nubes o en el mundo real. Pero sí parece que nos hemos perdido en un cuadro surrealista. El autor recrea una situación inmersiva donde nos circunda de pantallas gigantes y donde sin narración explicita y recurriendo primordialmente a lo sensorial, nos invita a reconciliarnos con nuestro interior mediante la apelación emocional. De nuevo, un retrato de nuestra insignificancia frente a la naturaleza. Pretende llevarnos a la conmoción donde

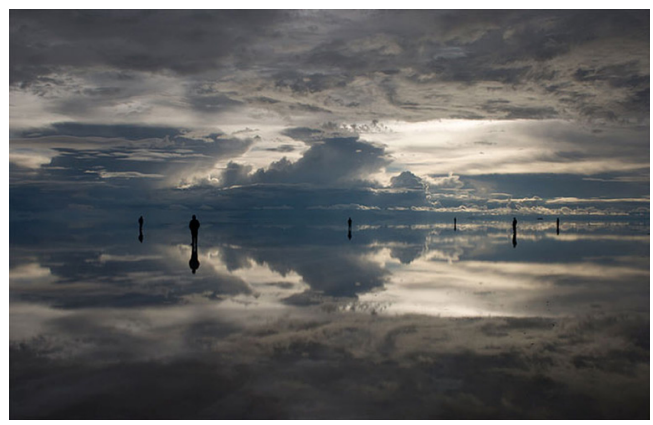

Fig. 5. Charly Nijensohn, El naufragio de los hombres, 2008. Videoinstalación, 3 canales, color $\left(7^{\prime} 28^{\prime \prime}\right)$, sonido, loop (https://www.youtube.com/watch?v=pZHo_R20_b8)

solo lo sublime llega. Esta obra es también un estudio perceptivo.

La línea del horizonte, o la inexistente línea en muchas secuencias debido al espejismo del cielo sobre el agua, es la protagonista de la obra. En este inmenso espejo el individuo pierde hasta su propio horizonte y cuesta distinguir entre lo irreal y lo real. Este recurso enfatiza aún más la soledad que intenta transmitir siempre. De nuevo, las siluetas negras, pero esta vez aún más perdidas divagando por la inmensidad. Enfatizan el mensaje existencialista. Esta obra es una poesía a su búsqueda metafísica. El recurso sonoro contribuye a la sensación de soledad: el silencio. En un espacio así tiene cabida cualquier interpretación y pensamiento que el individuo quiera debatir consigo mismo. Por otro lado, el cielo y la tierra (o el agua) vuelven a ser protagonistas. En otro tiempo, una obra de tales características se habría presentado como un marco ideal para hablar de dios. Pero, otro de los rasgos que caracterizan al paisajismo del siglo XXI, es que dios suele desaparecer. Por lo general, desaparece esa visión panteísta de la naturaleza. Todo suele girar en torno a la individualidad: al autoconocimiento del propio individuo. Una individualidad que, sin duda, caracteriza a los individuos de esta era.

Lukas Marxt (Austria, 1983) es un joven videoartista cuyo trabajo se centra en un dialogo continuo entre él y la naturaleza. Sus obras se caracterizan por una cuidadísima estética, por la sensación de soledad, pero siempre acompañada por la presencia del autor -como el "yo" romántico-, por planos que frecuentemente coquetean 


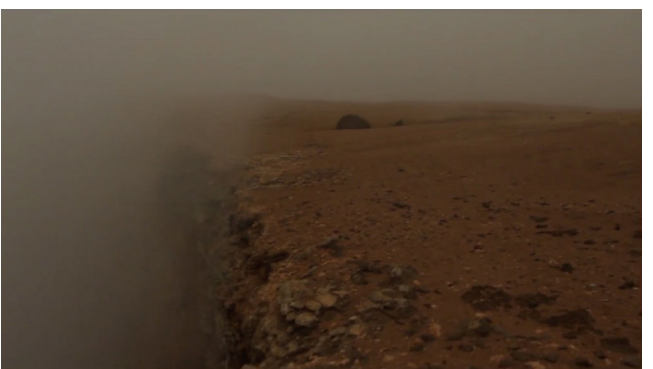

Fig. 6. Lukas Marxt, It Seems To Be Loneliness But it Is Not, 2012. Vídeo, color (37'), sonido, monocanal (https://vimeo. com/81338744)

con la idea de lo sublime, y unos paisajes que invitan a perderse para encontrarse. Sus obras nos devuelven a los vastos e inmensos paisajes de la Escuela del Río Hudson. Como un auténtico viajero romántico, Lukas es un explorador: ha viajado al Ártico, ha entrado en una mina de uranio en Australia para captar un doble eclipse, vivido en una plataforma petrolífera en mitad del Mar del Norte, se ha perdido en los desiertos californianos, ha pasado días deambulando por las montañas canarias y hasta ha llegado a las costas de Gana. Esto quizá explica que frecuentemente sus obras presenten un esteticismo que parece sacado de los reportajes de National Geographic. Marxt busca diálogar con la naturaleza, lo que explica esa necesidad de perderse en la inmensidad de los rincones más recónditos del planeta para reencontrarse a sí mismo:

A menudo visito lugares que me devuelven a mis necesidades básicas. Estas limitaciones son parte de un método de trabajo para usar mi percepción de manera más consciente y detectar instintos que no necesito en mi existencia normal. Es una explosión para demarcarme por un tiempo, para llevar una vida de acuerdo con mis propias reglas y las de la naturaleza (Tschütscher 2015).

Lukas busca retratar lugares remotos que supongan un desafío para la supervivencia del hombre. En una entrevista que tuvimos la ocasión de realizarle al artista austriaco ${ }^{14}$, Marxt nos habló de su concepción de un mundo postapocalíptico. Pero es fundamental entender que lo concibe desde una perspectiva constructiva y no desde una visión pesarosa. Como aceptando el mundo actual y, dándole un nuevo enfoque, crear nuevos paisajes. En su obra se entiende que somos parte del cambio y su trabajo reflexiona sobre de dónde venimos, dónde estamos y cómo lidiamos con ese cambio. Pero esta vertiente postapocalíptica de su arte se desvía ligeramente del objeto de este artículo y entra en el terreno de otros tipos de paisaje que hemos identificado. Y que también está muy relacionado con el concepto de "Entropía" de Robert Smithson"15. Pero, como explicábamos al principio, esta investigación parte de la consanguineidad de las artes y defiende que es imposible establecer límites entre las obras contemporáneas. Los paisajes de Lukas Marxt presentan una lectura romantizada de la naturaleza del Antropoceno: busca la belleza en la destrucción. Y, aunque pueda parecer contradictorio, desde su aceptación también se vislumbra, a veces, una cierta melancolía de lo que un día fue y ya no es. Una melancolía que ya mostraron los románticos. Sigue recurriendo a la idea de la naturaleza poderosa, virgen, inmensa y remota, como vemos en obras como Low Tide (2014, 3') o Reign of Silence $\left(2013,7^{\prime}\right)$.

Marxt, como hemos mencionado, es uno de esos artistas jóvenes que están ayudando a crear nuevos códigos estéticos, narrativos y conceptuales para la paisajística del siglo XXI. Uno de los rasgos que más caracteriza su obra es la utilización de la tecnología del dron -aunque, precisamente, la obra que presentamos aquí no presente esta particularidad-. Las vistas aéreas son otro de los rasgos que caracterizan a la paisajística del Antropoceno, pero no son algo nuevo. Recordemos que la fotografía ya las introdujo anteriormente, entre las que destacamos, indudablemente, las vistas aéreas de Nadar. Sus vídeos son pausados, dan tiempo al espectador para reflexionar, pero sin ser manipulado. Lukas plantea una situación e invita a reflexionar a través de tu propia experiencia. En Double Dawn (2014, 29') es, quizá, donde este concepto del deep time se manifiesta mejor. Un plano fijo de media hora de un evento natural: un amanecer y seguidamente un eclipse. El espectador, acostumbrado al frenetismo contemporáneo y al lenguaje de la TV o el cine, se impacienta ante la oscuridad y la expectación.

En It seems to be loneliness but it is not (2012, $\left.37^{\prime}\right)^{16}$ (fig. 6), el artista camina por las montañas de la isla volcánica de Lanzarote mientras que el espectador hace el camino junto a él. Desde el 
principio, sentiremos la herencia de Richard Long. Marxt no modifica nada, solo deambula por el entorno enriqueciéndose de la experiencia y dialogando con el lugar ${ }^{17}$. Esto nos devuelve también a los viajes del hombre romántico. El autor nos introduce en un escenario, pero sin darnos muchas premisas. Nos deja libres. Pretende que nosotros mismos creemos nuestras propias sensaciones y sentimientos. Además, el audio no ha sido manipulado y el tiempo transcurre a velocidad real. Muestra una naturaleza ardua, pero el artista, a través del modo en que se relaciona con ella, presenta un acercamiento agradable. La sensación de paz se apodera de la escena. La exaltación de la subjetividad es otra evidencia, esta obra podría caer en la crítica de ser una caminata documentada, pero la subjetividad de la cámara la desvincula de ello. Marxt presenta siempre una cámara muy subjetiva. Aquí encontramos muy bien retratada la idea del "yo" romántico. La cámara presenta una dualidad, pues encontramos el "yo" del artista, quien demuestra continuamente su presencia, pero también el "yo" del espectador que toma la lente como sus propios ojos. Sabemos que no estamos solos, sentimos la respiración de Marxt, caemos con él por la ladera, nos estremecemos al no poder avanzar, desconfiamos al adentrarnos en la niebla y sentimos el vértigo del barranco. Él presenta una serie de circunstancias y nosotros las interpretamos. La imagen es muy inestable, la cámara tiembla. No hay una narrativa explicita. El movimiento de la cámara nos perturba, el silencio puede ser incómodo y los fenómenos atmosféricos nos llevan a mantenernos siempre expectantes. Por otro lado, la estética volcánica está relacionada con su idea postapocalíptica. Nos sentimos reducidos en un lugar remoto donde nuestra supervivencia peligra. No hay agua, comida ni cobijo. Nos plantea la insignificancia de nuestra existencia desde una contradicción: somos tan "poderosos" que hemos conseguido destruir el mundo, pero, a la vez, somos nada.

Para finalizar, el último artista que aquí presentaremos es Gianfranco Foschino (Chile, 1983). La obra de Foschino es un excelente ejemplo de cómo, a partir de la reinvención del lenguaje romántico, se pueden crear nuevos códigos para desarrollar una nueva tradición paisajística. Su trabajo ha alcanzando tanto éxito que ha llegado a exponer en lugares tan prestigiosos como la $54^{\circ}$ y la $57^{\circ}$ Bienal de Venecia. Su praxis parte de la fascinación por entender el mundo. Especialmente, el movimiento y los ritmos naturales. Porque observar el exterior y conocer cómo funciona la naturaleza es la única forma de conocer bien nuestra identidad. Y cuando uno conoce bien quién es, no puede "perderse". Para ello viaja a lugares remotos del planeta, él también es un explorador. Mediante sus "pinturas" en movimiento, Foschino debate temas que tienen que ver con la metafísica tradicional, pero también con una metafísica genuinamente contemporánea. Sus obras obligan a detenerse, a pausar el ritmo vertiginoso de la vida actual y contemplar los fenómenos maravillosos que nos regala la naturaleza:

Asumo este acto de contemplación como una especie de rito solitario de aprendizaje, solo así puedo concentrarme en el ritmo inherente. Siempre me he sentido como un un niño que observa el mundo como algo extraño. Acudo a la naturaleza con ánimos de sorprenderme, de descubrir fenómenos descritos en libros y que no son apreciables dentro de las ciudades. Vivimos en un mundo de tiempos variables y rescatar imágenes del devenir constante del tiempo ha sido mi obsesión. Observar el movimiento de una nube, el paso del agua que corre o los cambios de luz para evidenciar que todo está sometido al tiempo, todo es puro cambio constante y ninguna tecnología será capaz de contrarrestarlo. Eso me preocupa y me genera nostalgia ${ }^{18}$

Para enfatizar esta búsqueda, Foschino desarrolla una práctica artística basada en unos aspectos formales que ya le caracterizan: obras enmarcadas como un cuadro, una imagen en movimiento captada por una cámara siempre situada desde en un punto de vista fijo, silencio y tiempo a velocidad real. Esto provoca una gran contradicción en el espectador. Su obra es una continua confrontación entre la tradición y lo contemporáneo. Entre los códigos de la pintura, de la fotografía y los del videoarte. Sus obras se acercan alarmantemente a la pintura, devolviendo la imagen en movimiento a lo que en esencia es, "imagen", y dotando de un papel secundario a los aspectos formales del formato audiovisual, que suelen ser los protagonistas. Podríamos decir que Gianfranco Foschino pictorializa el tiempo y 


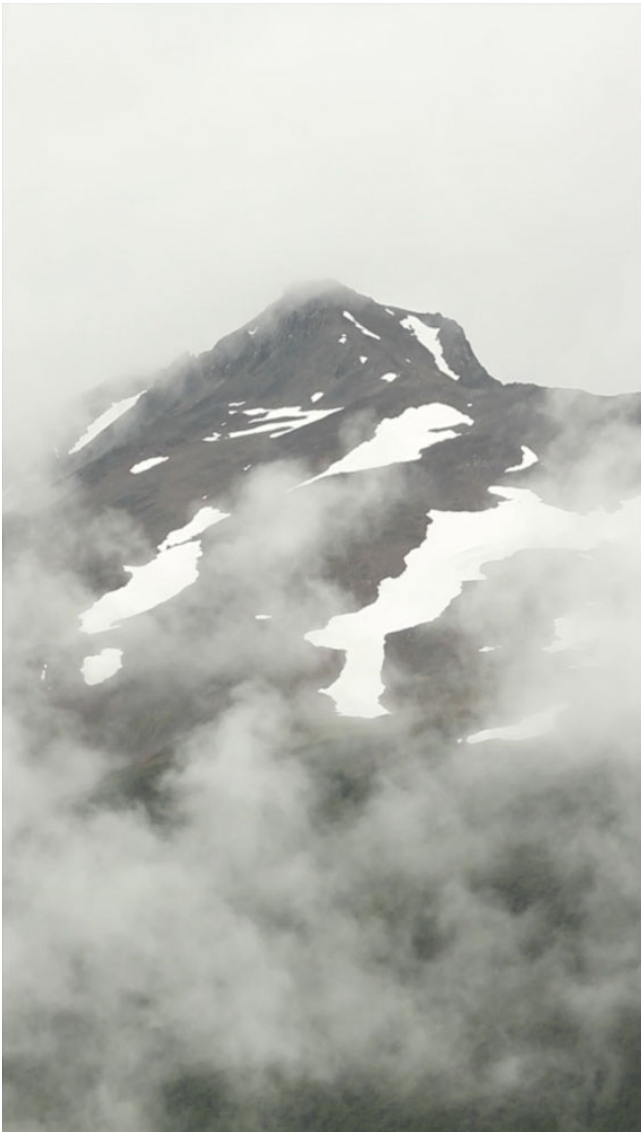

Fig. 7. Gianfranco Foschino, Cima, 2016. Vídeo HD, color (11'), sin sonido, monoconal, loop (https://vimeo.com/229305830)

el movimiento, a diferencia de lo que el arte ha perseguido a lo largo de su historia intentando dinamizar la imagen, como, por ejemplo, hicieron los futuristas. Sus paisajes son auténticos lienzos de LED. Esto contribuye a que el espectador no se sienta incómodo en su acercamiento al videoarte, como suele ocurrir. Sus obras se caracterizan por esa bidimensionalidad entra la quietud y el dinamismo. Por esa materialización de la imagen en movimiento, devolviendo algo tan inmaterial como es el vídeo al concepto de obra como objeto fetiche. Pero, también, los marcos blancos -que contribuyen a la idea de cuadro- recuerdan la importancia del marco en el paisaje. Dado que el paisaje es una "porción" subjetivizada de la naturaleza, es el concepto de "límite", de "marco" otra de las características que diferencia al

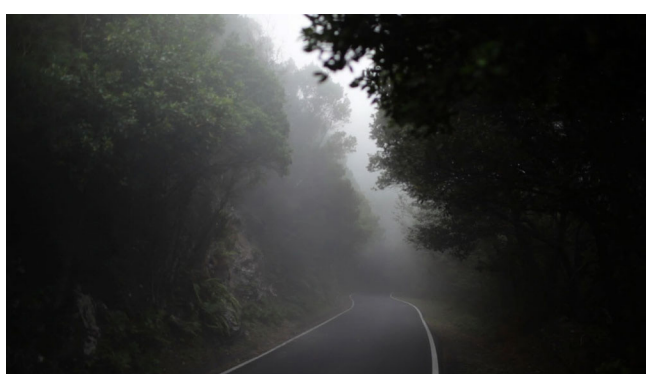

Fig. 8. Gianfranco Foschino, Espiritu Santo \#1, 2013. HD, videoinstalación, 2 canales (6') color, sin sonido, loop (https:// vimeo.com/75973203)

país del paisaje. En la misma línea, Foschino respeta la composición clásica del paisaje en todas sus obras, contribuyendo al pictorialismo. Esto se enfatiza mediante otros dos recursos: el punto de vista fijo y el silencio. Los cuales Foschino también utiliza como herramientas para enfatizar esa reconciliación que busca del espectador con los ritmos de la naturaleza. Para Foschino el silencio posibilita darle a la imagen la facultad de expresar su esencia -en este caso, el movimiento y los ritmos de la naturaleza- sin distracciones. $Y$ para esto también es necesario un punto de vista fijo (figs. 7 y 8$)^{19}$.

Cima (2016) ${ }^{20}$ y Espíritu Santo \#1 (2013) ${ }^{21}$ son dos trabajos que ejemplarizan de manera muy certera lo que venimos tratando. Son obras donde no hay narratividad, pero sí un fuerte conceptualismo. Apelan a la pura sensorialidad para trasmitir su mensaje. En ellas se presentan todos los elementos formales y conceptuales que acabamos de comentar, puesto que la trayectoria artística de Foschino sigue un hilo continuo que permite un análisis transversal. La presencia de elementos románticos es incuestionable. En Cima, la montaña amenazante, la desprotección, la niebla, la soledad, el frío que transmite la nieve, la escala tonal de colores apagados, la inmensidad o la presencia del "yo", sintiéndonos un poco como un "monje frente a la montaña". Un monje, además, diminuto. Mientras que, en Espiritu Santo, la carretera a ningún lugar que se pierde, o, quizá, una carretera a un lugar en concreto, la niebla, la soledad, el bosque cerrado, la expectación o el silencio. La carretera como una metáfora del viaje del alma, aunque aquí ya no se viaja en barcos como retrataban Turner 
o Friedrich, sino en coche. El marco puede ser limitado, pero el horizonte se presenta infinito. Son elementos que ya podrían haber sido sacados de una pintura de paisaje del XIX. Comentaba el curador Justo Pastor (2016) acerca de los loci horribili y los loci amoeni y de cómo la obra de Foschino transforma ese horror en belleza sublime. Pero, quizá "transformar" no sería el termino acertado. Foschino no transforma, sino que su trabajo nos devuelve de nuevo a la tesis de Argullol. Recordemos que este defendía que la pintura de paisaje romántica no es una mera manifestación artística, sino una determinada comprensión de la naturaleza. Foschino ansía reconciliarse con esta naturaleza a la que reconoce estar sometido y, de nuevo, como Argullol sostenía que hacían los románticos, él también desantropomorfiza. Estas obras son puro tecnorromanticismo. Una oda audiovisual a la belleza y a la destrucción.

\section{Conclusión}

Así pues, concluimos que, tras una revisión del panorama videoartístico, hemos localizado numerosas prácticas que conforman una nueva tradición paisajística. Hemos identificado un conjunto de prácticas que, a partir de las nuevas tecnologías, los intereses de los individuos del siglo $X X I$, y los nuevos lenguajes propios de esta era -como, por ejemplo, el audiovisual- reinterpretan los códigos románticos; como pueden ser la soledad, lo sublime, la desantropomorfización de la naturaleza, recursos formales como el camino, el viaje, la niebla o la montaña, así como una continua búsqueda de conexión espiritual o la inmensidad y vastedad de la representación de la naturaleza, por ejemplo, todos ellos elementos que hemos visto en las obras estudiadas. Hemos de decir también que hemos localizado muchos más artistas -como Bill Viola, Richard T. Walker o Dan Hudson, por ejemplo-y obras de las aquí presentadas. Como comentamos al principio, estas prácticas de videopaisaje no han sido nunca confrontadas o reunidas entre ellas, lo cual ha dificultado el trabajo de campo. Pero las coincidencias en torno al tratamiento de la imagen, la base conceptual y el lenguaje empleado en numerosos y diferentes artistas no puede ser casual. Tanto las preocupaciones de orden temático que conforman el imaginario de sus praxis como el medio en el que trabajan coinciden. Por tanto, podemos hablar de "videopaisaje» $y$, dentro del videopaisaje, de un videopaisaje tecnorromántico; donde estos códigos y aspectos formales que caracterizan al Romanticismo se reinterpretan aquí a partir de las posibilidades que brindan los medios con los que trabajan los artistas hoy -y, podríamos decir, incluso se enfatizan mediante las posibilidades perceptivas e inmersivas que ofrecen estos paisajes-, respondiendo a las demandas del arte y la sociedad de hoy. El paisaje romántico se desmarcó de la tradición que le precedía por el profundo mensaje que se escondía tras sus representaciones, una particularidad que se denota también en estos paisajes que, aunque parezcan singularizarse por sus cualidades técnicas y formales, la realidad es que, siguiendo el conceptualismo que caracteriza al arte contemporáneo, las obras esconden voraces críticas y reflexiones de índole social, política y ética. Somos conscientes de que es un campo muy amplio y aún debemos seguir trabajando, pero esta investigación ha identificado una realidad ignorada, y sienta las bases para que tanto nosotros, como otros investigadores, trabajemos en la conservación de estas nuevas prácticas artísticas. 


\section{NOTAS}

1 Goethe citado por Anwandter, Juan. 2015. "Aproximaciones al tiempo como materia: dos muestras de Gianfranco Foschino". Artishock, 29 de diciembre, 2015. http://artishockrevista. com/2015/12/29/aproximaciones-altiempo-materia-dos-muestras-gianfranco-foschino.

2 Yayo Herrero en discusión con Alicia Puleo, Joaquín Araujo y Raúl de Tapia durante la conferencia "Cultura y Medioambiente" organizada y divulgada por Radio 3. http://www.rtve.es/ alacarta/videos/cultura18/video-culturamedioambiente/4573100/.

3 Las teorías de la percepción se pusieron muy de moda en los sesenta, especialmente en EE. UU. Estas llegaron a través de las filosofías y religiones orientales a través del movimiento hippie. E introducirán nuevas vías de interpretación y de pensamiento.

4 En la historia del videoarte distinguimos dos etapas: una primera, desde la segunda mitad de la década de los sesenta y los setenta, y una segunda, desde los ochenta a hoy. Las características técnicas y las premisas conceptuales han cambiando debido al desarrollo tecnológico (sobre todo desde la digitalización de la imagen y el desarrollo de los softwares para su manipulación). En la primera etapa, las obras se caracterizan por perseguir la experimentación de la imagen cinética, la autorreferencialidad y las posibilidades que ofrecía el formato vídeo, así como marcar distancias con la TV y el cine y reivindicar su pertenencia al campo de las artes visuales. Mientras que, en la segunda etapa, encontramos una praxis conformada que se centra en cuestiones que se acercan más a las preocupaciones del arte y menos a la experimentación téc- nica, como, por ejemplo, el surgimiento de los "géneros" videográficos.

5 El tema de "la tematización de la mirada" en la pintura impresionista ha sido estudiado por Stoichita, Victor I. 2005. Ver y no ver. Madrid: Siruela.

6 En junio de 2017, en la feria de videoarte LOOP Barcelona, pudimos conversar brevemente con Mary Lucier.

7 Esta citación pertenece a la conversación aún inédita con la artista en junio de 2017. Será publicada junto a la investigación que motiva este artículo.

8 Electronic Arts Intermix. "Mary Lucier". Consultado: 20/9/2018. http:// www.eai.org/artists/mary-lucier/biography.

9 Esta cita pertenece a una entrevista aún inédita realizada al artista en enero de 2019. La entrevista será publicada junto a la investigación que motiva este artículo.

10 Se entiende por "preguntas de la condición humana" al conjunto de preguntas que en filosofía se encajan dentro de la rama de la metafísica. Los temas de la metafísica se pueden agrupar en tres grandes cuestiones: el mundo, el ser humano y dios. Preguntas que todos los seres humanos se hacen durante su vida. Como, ¿de dónde venimos? ¿qué hay después de la muerte? ¿existe un dios? $\mathrm{Y}$ un gran etcétera. Básicamente, aquellas preguntas que somos incapaces de responder. En muchas culturas a lo largo de la historia la respuesta a estas cuestiones se ha encontrado en las convicciones religiosas.

11 La crítica suele presentar la obra de Nijensohn como carente de narrativa, pero lo cierto es que el solo hecho de plantear una escenografía es ya un inicio de narración.
12 La obra puede visualizarse aquí: https://www.youtube.com/ watch? $v=94 \mathrm{fvxlHmpRc}$.

13 La obra puede visualizarse aquí: https://www.youtube.com/ watch? $v=p Z H o \_$R20_b8.

14 En diciembre de 2017, pudimos realizarle una entrevista a Lukas Marxt. La entrevista será publicada junto a la investigación que motiva este artículo.

15 Robert Smithson anticipó las teorías del Antropoceno con su concepto de paisaje entrópico en su ensayo "Entropía y los nuevos monumentos", publicado en ArtForum en 1966 y recogido en Smithson, Robert. "Entropy and the New Monuments." En The Writings of Robert Smithson, edited by Nancy Holt, 9-19. New York: New York University Press, 1979

$16 \quad$ Aquí https://vimeo. com/81338744 puede visualizarse parte de la obra. Somos conscientes de que el acceso a la videografía de Marxt es límitado al público. Pero el artista nos ha brindado la posibilidad de visualizar su videografía de manera privada para poder analizar adecuadamente su praxis.

17 Esta práctica del caminar es profundamente estudiada en Careri, Francesco. 2007. Walkscapes: el andar como práctica estética. Barcelona: Gustavo Gili. El autor defiende el deambular como un acto cognitivo capaz de transformar tanto el espacio natural como el antrópico.

18 Esta citación pertenece a una entrevista aún inédita realizada al artista en enero de 2019. La entrevista será publicada junto a la investigación que motiva este artículo.

19 Ibid.

20 La obra puede visualizarse aquí: https://vimeo.com/229305830.

21 La obra puede visualizarse aquí: https://vimeo.com/112594999. 


\section{REFERENCIAS}

AA.VV. Charly Nijensohn. Estado de emergencia. Buenos Aires: Fundación Telefónica, 2014.

Anwandter, Juan. "Aproximaciones al tiempo como materia: dos muestras de Gianfranco Foschino." Artishock, diciembre 29, 2015. Consultado: 08/11/2018. http://artishockrevista.com/2015/12/29/aproximaciones-altiempo-materia-dos-muestras-gianfrancofoschino.

Argullol, Rafael. La atracción del abismo. Barcelona: Destino, 1983.

Balsom, Erika. "Why are Artist Filmmakers turning to Landscapes?" Frieze, abril 16, 2018. Consultado: 06/12/2017. https://frieze.com/ article/why-are-artist-filmmakers-turninglandscape.

Barlow, Melinda, ed. Mary Lucier. Maryland: The Johns Hopkins University, 2000.

Careri, Francesco. Walkscapes: el andar como práctica estética. Barcelona: Gustavo Gili, 2007.

Cauquelin, Anne. L'invention du paysage. París: Presses Universitaires de France, 2013. https:// doi.org/10.3917/puf.cauq.2013.02.

Electronic Arts Intermix. "Mary Lucier." Consultado: 20/09/2018. http://www.eai.org/artists/ mary-lucier/biography.

Foschino, Gianfranco. Cima. 2016. Consultada en repetidas ocasiones entre noviembre de 2018 y enero de 2019. https://vimeo. com/229305830.

Foschino, Gianfranco. Espíritu Santo. 2013. Consultada en repetidas ocasiones entre noviembre de 2018 y enero de 2019. https://vimeo. com/112594999.
Maderuelo, Javier. "Aquello que llamamos paisaje." Visions de l'Escola Técnica Superior d'Arquitectura de Barcelona 2 (2003): 20- 25.

Maderuelo, Javier. El paisaje: génesis de un concepto. Madrid: Abada, 2005.

Marxt, Lukas. It seems to be loneliness but it is not. 2012. Consultado reiteradas veces entre marzo de 2018 y enero de 2019. https://vimeo.com/81338744.

Nijensohn, Charly. Dead Forest, 2009. Consultado reiteradas veces entre noviembre de 2017 y enero de 2019. https://www.youtube.com/ watch?v=94fvxlHmpRc.

Nijensohn, Charly. El naufragio de los hombres. 2008. Consultado reiteradas veces entre noviembre de 2017 y enero de 2019. https:// www.youtube.com/watch?v=pZHo_R20_b8.

Nijensohn, Charly. "Sur Global: una mirada sobre el espacio americano". 2015. Consultado: 15/04/2018. https://www.youtube.com/ watch?v=JRhYYAADPhA.

Pastor Mellado, Justo. "Gianfranco Foschino: Locus." Artishock, Agosto 6, 2016. Consultado: 13/12/2018. http://artishockrevista. com/2016/08/06/locus-gianfranco-foschino/.

Roger, Alain. Breve tratado del paisaje. Madrid: Biblioteca Nueva, 2007.

Smithson, Robert. "Entropy and the New Monuments." En The Writings of Robert Smithson, edited by Nancy Holt, 9-19. New York: New York University Press, 1979.

Stoichita, Victor I. Ver y no ver. Madrid: Siruela, 2005.

Tschütscher, Dominik. "Talents to watch: Lukas Marxt." Cinemanext, marzo, 2015. Consultado: 06/12/2017. http://www.cinemanext.at/ talents-to-watch/lukas-marxt. 
